\title{
INCORPORATION OF CIRCULAR ECONOMY CONCEPT TO THE APPAREL INDUSTRY: LITERATURE REVIEW
}

\author{
GOWSIGA M. ${ }^{1} \&$ THAYAPARAN M. ${ }^{2}$ \\ ${ }^{1,2}$ Department of Building Economics, University of Moratuwa, Sri Lanka. \\ 1gowsigam@uom.lk, ${ }^{2}$ mthayaparan@uom.lk
}

\begin{abstract}
The apparel industry is one the most foreign exchange earning industries for developing countries. However, it is one of the notable polluting industries in the world too. Additionally, there are numerous factors affecting the economy of the industry, for example COVID 19, and the industry needs to reinvent from those issues by forcing itself to live. Thus, Circular Economy (CE) can act as a potential solution to address the issues related to both environmental and economic factors of the apparel industry. $\mathrm{CE}$ is a business strategy to gain economic benefit, minimise environmental impacts and increase the efficiency of resource consumption. CE concept has been practised in various countries such as China, Bangladesh, Europe, Australia and Germany. However, it is still a novel concept in Sri Lanka even though Sri Lankan apparel industry has a solid reputation globally for their high-quality, reliability, lead time, and social accountability. Introducing the CE concept into Sri Lankan apparel industry will help to overcome the financial issues in a sustainable way. With the intention of introducing CE concept to Sri Lankan apparel industry, this paper intends to review the application of CE in global context and in the context of apparel industry, their benefits and challenges in order to further investigate the suitability of CE concept to SL apparel industry. This paper is therefore based on a comprehensive literature review. Hence, it highlights the literature findings on the applicability of CE in apparel industry, its benefits and challenges when adopting CE into apparel industry. This basic finding will aid to assess the possibility of incorporating CE concept within the Sri Lankan apparel industry. The key findings of the research, environmental gain, economic benefit, resource optimisation and collaboration among stakeholders are the key benefits of CE. The main challenges are expensive, advanced technology, measuring the benefits especially financially, lack of support, knowledge, awareness, commitment and leadership, systematic regulation, social and cultural acceptance.
\end{abstract}

Keywords: Circular Economy, Apparel Industry, Challenges, Benefits

\section{Introduction}

The ability to produce apparel at extremely low cost has allowed the apparel industry to grow into a trillion-dollar industry, now one of the largest globally (Allwood, et al., 2006). It has experienced extensive growth and success over the last two decades and also the most significant and dynamic contributor to the national economy of developing countries (EDB, 2020). This has led to an intense scrutiny over economic, environmental, and social impacts within the industry. The apparel industry has specific negative impacts on the environment through all stages of the apparel product life cycle, from fiber growth and manufacturing, dyeing and printing, transportation to stores and selling, to end of the garment life disposal (Allwood, et al., 2006; Shaw, et al., 2006; Gam \& Banning, 2011; Fulton \& Lee, 2010). The Earth cannot indefinitely support the current level of production and disposal of apparel due to depletion of natural resources and quickly filling landfills (Claudio, 2007; Walker, 2008; Winge, 2008). Along with that, the attention in sustainable and eco-friendly products has started to increase globally (Muthukumarana, et al., 2017).

$\mathrm{CE}$ is a fresh economic model in contrast to the linear economic model, adapted by China at first. CE initiatives happen in global level (Ghisellini et al., 2016). The ultimate aim of CE is to achieve the decoupling of economic growth from natural resource depletion and environmental degradation (Liu, 2009; Xue et al. 2010), to keep the maximum level utility and value of the products and materials, through design, maintenance, repair, reuse, remanufacturing, and recycling and decreasing waste (Merli, et al., 2018). CE is a regenerative structure in such a way that resource input waste, emission, and energy use are minimised by closed loops of material and energy (Geissdoerfer, et al., 2017). The conversion of $\mathrm{CE}$ from a linear economy requires organisations to redesign their supply chain. Thus, $\mathrm{CE}$ is effective to promote to the green supply chain from the traditional chain (Zhu, et al., 2010). Also, in $\mathrm{CE}$, a need to propose a business strategy raised to gain economic benefit, minimise environmental impacts and increase the efficiency of resource consumption (Zhu \& Sarkis, 2006; Lai, et al., 2011). It is CE that further strengthens the consciousness of resource conservation and environmental protection (Ying \& Li-Jun, 2012). Moreover, CE highlights protecting the environment and conserving the resource, thus, it is important to go beyond green manufacturing to GSCM. 
Meanwhile, the apparel industries have started to fight for its survival due to COVID-19 (Echelon Media, 2020). For example, in Sri Lanka roughly 1.5 billion American dollar loss is expected in export incomes in the quarter of April-June 2020, while bracing for a 50\% drop in demand for the next one to one and a half years (Sukumaran , 2020). Therefore, the industry should be in a position to reinvent by forcing itself to live (Echelon Media, 2020). Thus, CE could be a sustainable way to overcome this phenomenon. Accordingly, this is the best time to introduce the Circular Economy concept into apparel industry to overcome the economic issues in a sustainable way. The next section presents the methodology adopted for this paper followed by introduction, need and application of CE in the context of apparel industry. Further it discusses the benefits and challenges of adopting CE concept within apparel industry. The conclusions and way forward are finally presented.

\section{Research method}

This research paper was developed based on a comprehensive literature review and synthesis on the $\mathrm{CE}$ concept, its significance and the reported evidences on the incorporation of CE within apparel industry. It further reviewed the benefits and challenges associated with the adoption of CE concept. Conducting literature review is facilitating to initiate the research process when carrying out a research work. In a research, literature synthesis is a significant portion and according to Wilding, et al., (2012), a literature review is a systematic, explicit, and reproducible design for identifying, evaluating and interpreting the existing body of recorded documents" and further literature review is defined as primarily qualitative synthesis of results (Fink, 2005). Hence this paper adopts the literature review as the main methodology to present the research findings.

The literature search operation was facilitated by using a combination of keywords such as 'Circular Economy', 'Circular economy \& Apparel industry', "Circular economy” \& "Textile industry”, and 'Benefits and challenges of CE'. The key journal articles published within last 10 years were mainly searched using main databases such as Google scholar, Emerald, Science Direct, Springer, etc. A total of 69 articles was selected after the first round of filtration, which involved scanning article titles for relevancy. The second round filtration was done to further refine the set of articles by reading the abstracts and conclusions, which resulted in 57 papers. While reviewing the full papers, 5 of the papers were found as not appropriate. Hence, 52 papers were finally identified to develop this literature review based paper.

\section{Literature Synthesis}

This section discusses the key literature findings of the study in four sub sections such as introduction to $\mathrm{CE}$, need for $\mathrm{CE}$ in apparel industry, application of $\mathrm{CE}$ in apparel industry and benefits and challenges of adopting $\mathrm{CE}$.

\subsection{INTRODUCTION TO CIRCULAR ECONOMY}

$\mathrm{CE}$ has both linguistic and descriptive meaning. The linguistic meaning of $\mathrm{CE}$ is an antonym of a linear economy (Murray, et al., 2017). Linear economy is a straight-line process; 'take-make-dispose' approach (open loop) with energy flow model whereas the CE is a cyclical approach (closed loop) with alternative flow model where wastes become resources (Gregson, et al., 2015; Braungart \& McDonough, 2002). Even though, Linear economy is expected to have unlimited resources and energy for usage and also bulk environment to absorb the discharged waste and pollution, $\mathrm{CE}$ is idealised for reduction in the amount of energy and raw material usage with less waste generation (Cooper, 1999). Primarily, linear economy is an unsustainable economic system and it has dominated the overall development causing serious environmental harm, but on the other hand, CE is a sustainable economic system (Ellen Macarthur Foundation, 2014). Moreover, CE is based on natural laws which following natural cycle (Twigger, 2016), and four principles such as natural resource preservation, resource optimisation, risk reduction and renewable flow of resources and products (Gullingsrud \& Perkkins, 2015). Figure 1 visualizes the linear and circular supply chain. 

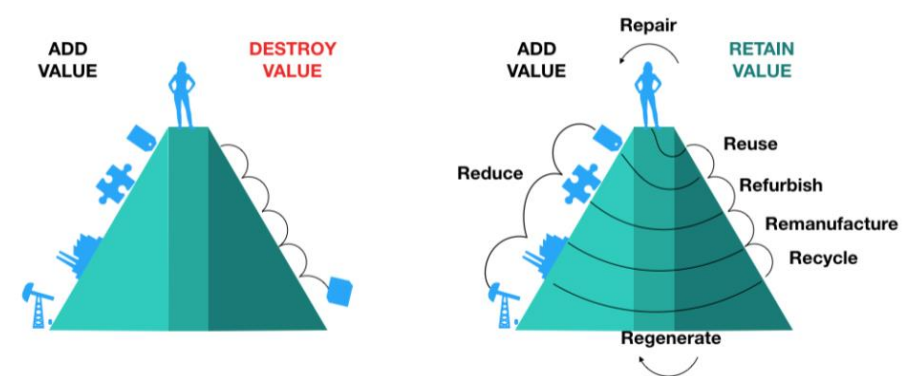

Figure 1: Visualization of linear and circular supply chain.

Source: (Achterberg, et al., 2016)

The descriptive meaning of $\mathrm{CE}$ is related to the theory of the cycle, which contains two cycles, biogeochemical cycles and the idea of products recycling (Murray, et al., 2017). CE concept is basically balancing the development of economy with protection of environment and resource (UNEP, 2006). Further, Ellen MacArthur Foundation (2017) defined "A CE aims to redefine growth, focusing on positive society-wide benefits, it gradually decoupling economic activity from the consumption of finite resources, and designing waste out of the system (Rattalino, 2017). Likewise, there are a number of definitions and multiple principles of CE exist in the literature (Prieto-Sandoval, et al., 2017; Pompon \& Moncaster, 2016). The following four components are recognised as essential to establish the $\mathrm{CE}$ concept through a research analysing more number of CE definitions which are 1) the recirculation of resources and energy, the minimisation of resources demand, and the recovery of value from waste, 2) a multi-level approach, 3) its importance as a path to achieve sustainable development, and 4) its close relationship with the way society innovates (Prieto-Sandoval, et al., 2017).

Moreover, a conceptualised definition for CE was derived from Kirchherr, et al. (2017) who have defined CE, after analysing 114 definitions, as an economic system that replaced the 'end-of-life' model through reduction, alternative reuse, recycling and recovering materials in production, distribution and consumption processes. Moreover, authors stated that the aim of the CE concept is to achieve sustainable development which simultaneously generates viable natural environmental, economic prosperity and nurturing community (Wu, 2005; Shen, 2007). Further, it is an industrial system concentrated on closing the loop for material and energy flows and contributing to long lasting sustainability (Genovesea, et al., 2017). Additionally, CE integrates strategies and policies for optimise energy efficient, materials, and water consumption, whereas waste discharging to the environment is minimal (Geng, et al., 2013). Furthermore, the closed loop economy and design to redesign thinking are the two concepts that are the causes for the uniqueness of $\mathrm{CE}$ and also it contains low energy consumption, less pollutants emission and high efficiency (Murray, et al., 2017). To conclude, CE highlights the repair, reuse, refurbishment, remanufacturing, cascading and upgrading of materials, products and components, in addition renewable and waste-derived energy consumption all through the value chain of the product and cradle-to-cradle life cycle (Mihelcic, et al., 2003; Braungart, et al., 2007).

\subsection{NEED FOR CIRCULAR ECONOMY IN APPAREL INDUSTRY}

The apparel industry is having a resource-intensive supply chain which pollutes water, soil and air; as a result it is one of the notable polluting industries in the world (Leonas, 2017). Considerable amount of $\mathrm{CO}_{2}$ is emitted during the production of petrochemicals, from which more than $60 \%$ of textile fibres are derived and balance are ruled by cotton which lead to toxic pollution, by rigorous pesticides usages (Sandin \& Peters, 2018). Most elements of apparel supply chain have negative impacts on the environment as samples dyeing, finishing, printing are emitting toxic substances, and spinning weaving, knitting are relying on fossil energy (Roos, et al., 2015). In addition, greenhouse gas emissions, usage of water, discharge of toxic substances and huge waste generation are the leading environmental issues for the apparel industry (Allwood, et al., 2006). Thus, to overcome the 
aforementioned challenges, the need for CE concept is raised. The implementation of CE could reduce the virgin fibre production and which lead to avoid engineering processes further downstream in the textile product life cycle, and thus reduce environmental impact as well (European Commission (EC), 2008).

Conventional approaches to solve the matters relating to waste, sustainability, and resource depletion have not addressed a complete image to attain sustainability (Martin, 2013). Moreover, to support communities in achieving a sustainable growth, the need for a CE has been widely acknowledged (Ghisellini, et al., 2016). Thus, CE has the potential to solve the gap resulting from natural resource scarcity and global growing population or consumption, especially when the relationship between resource use and waste residuals is considered (Andersen, 2007). Other than the environmental factors, CE can act as a potential answer for economic loss of the apparel industry and it provides economic efficiency to the organisations (Geissdoerfer et al. 2017; Haas et al. 2015; Park et al. 2010) which covers a technique of economic value making. Figure 2 shows an example about how CE effecting on material demand, it would reduce the amount of material consumed to a lower set point.

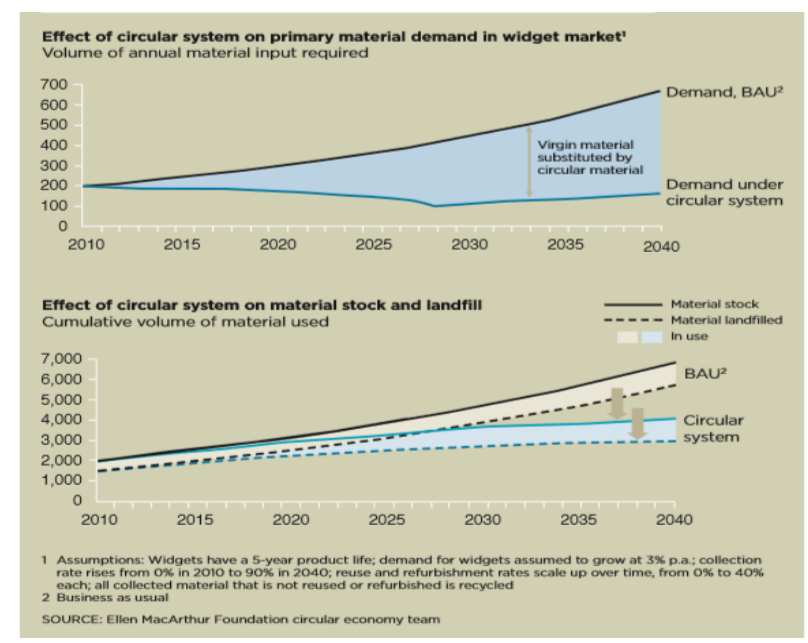

Figure 2: Effects of CE on material demand

The above graph clearly highlights the generous savings result through circular arrangement by showing the variances among the businesses as usual (BAU) and the circular scenarios of both fresh virgin materials required and the build-up of stock.

\subsection{APPLICATION OF CIRCULAR ECONOMY IN APPAREL INDUSTRY}

Several countries have adopted the CE model to attain environmental and economic sustainability; some of those are China (Korhonen, et al., 2018) Europe (Gregson, et al., 2015), Bangladesh (Moktadir, et al., 2017), Australia (Giurco, et al., 2014), Dutch (Fischer \& Pascucci, 2017), Denmark (Tajuddin , 2019), Brazil (Amaral, et al., 2018) and Romania (Staicu \& Pop, 2018). CE is applicable for all the industries and among those it is widely used in apparel industry. Certain leading apparel manufacturing organisations in the multinationals viewpoint such as H\&M, Inditex and Bestseller have adopted $\mathrm{CE}$ models already for the environmental and economic benefits. Likewise, PUMA has established a new track for shoes and clothing named as INCYCLE ${ }^{\mathrm{TM}}$, which consists in biodegradable or recyclable products where all certified Cradle-to-Cradle ${ }^{\mathrm{TM}}$ (Ellen MacArthur Foundation, 2013). The Figure 3 summarises some of the classification of textile reuse and recycling route. Textile recycling is mostly discussing as the reprocessing of pre or post-consumer waste of textiles which is used either in new textile or non-textile products. Generally, it is classified as mechanical, chemical and thermal; however, it is unclear and debatable. Thus, this summarization was based on the disassembly level of the recovered material. 
Fabric recycling used when the fabric is recovered and reused in new products, Fibre recycling is used when the fabric is dissembled, but preserved with original fibres, Polymer/Oligomer recycling is referring as the fibres are dissembled, but preserved with the polymers/oligomers and Monomer recycling is referred as the polymers/oligomers are dissembled, but preserved with the monomers. Additionally, closed loop and open loop recycling were considered here. Closed-loop and open-loop recycling are referring to when the material of a product is recycled and used in an identical product, in another product respectively. Whereas Figure 4 provides an overview of the fibre content of the materials being reused or recycled, and the type of recycling routes is employed. Here, numbers correspond to the number of cases examining reuse, or a specific recycling route, for a certain material.

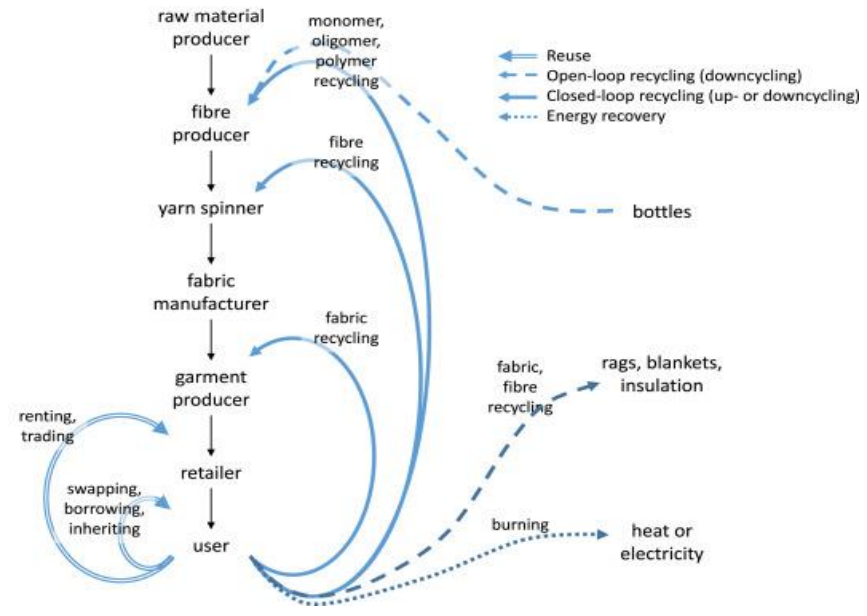

Figure 3: A classification of various forms of reuse and recycling. Source: (Sandin \& Peters, 2018)

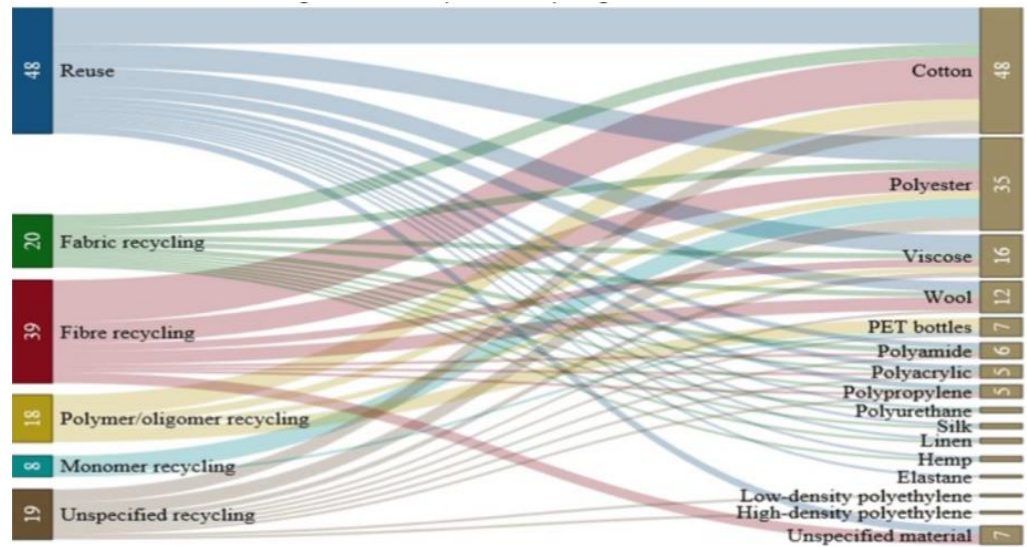

Figure 4: An overview of the fibres content of the materials being reused or recycled, and the type of recycling routes being employed

Source: (Sandin \& Peters, 2018)

Above figure 4 was developed based on a literature analysis on environmental assessments of textile reuse and recycling using 41 publications. 57\%, 37\%, 23\% and 14\% are the percentages of studies carried out on fibre recycling, polymer/oligomer recycling, monomer recycling and fabric recycling. The high prevalence of fibre recycling is probably due to the fact that it is a relatively common recycling route, widely applied in commercial scale both in terms of open loop and textile-to-textile recycling. 


\subsection{BENEFITS AND CHALLENGES OF ADOPTING CIRCULAR ECONOMY}

\subsubsection{Benefits of adopting Circular Economy}

The adoption of CE provides multiple benefits that are listed in Table 1.

Table 1: Benefits come through adoption of Circular Economy

\begin{tabular}{|c|c|c|c|c|c|c|c|c|}
\hline \multirow[t]{2}{*}{ Code } & \multirow[t]{2}{*}{ Benefits } & \multicolumn{6}{|c|}{ Sources } & \multirow[t]{2}{*}{ Count } \\
\hline & & $\mathbf{1}$ & 2 & 3 & 4 & 5 & 6 & \\
\hline B1 & Environmental gain & * & * & $*$ & $*$ & & $*$ & 5 \\
\hline B2 & Economic benefit & * & * & $*$ & * & & & 4 \\
\hline B3 & Resource optimisation & & $*$ & * & * & & * & 4 \\
\hline B4 & Collaboration among stakeholders & * & * & & & & & 2 \\
\hline B5 & Extended producer responsibilities & & & & & * & & 1 \\
\hline B6 & Eco friendly labeling & & & & & * & & 1 \\
\hline B7 & Respond quickly to market demand & & & & & & * & 1 \\
\hline B8 & Promote industrial upgrading & & & & & & * & 1 \\
\hline B9 & Improve the energy efficiency & & & & & & * & 1 \\
\hline B10 & Sustainability & & & * & & & & 1 \\
\hline B11 & $\begin{array}{l}\text { Connectivity of material streams - } \\
\text { cluster collaborations }\end{array}$ & & * & & & & & 1 \\
\hline B12 & Design for end-of-life & & $*$ & & & & & 1 \\
\hline B13 & Enhance job growth & & & & * & & & 1 \\
\hline
\end{tabular}

Environmental gain has been identified as the significant benefit come through adopting CE which means mainly the reduction of environmental pollution. Then, economic benefit and resource optimisation have been mentioned in four sources. The cost savings presented by more widespread recovery and reuse. Also, the Resource optimisation comprised of resource productivity, optimise research usage, allow the necessary time and space for natural resource regeneration and avoid natural resource depletion. Moreover, Collaboration among stakeholders includes both collaboration among organisational and environmental collaboration with customer and suppliers. In addition, Eco friendly labelling, The European commission (2012) introduced eco labelling. This is a label, which gives promise to the consumer that the product is sustainable and produces little waste. This labelling is not yet common for textiles but is seen as an opportunity for the future to gain legitimacy.

\subsubsection{Challenges to adopt circular economy}

Adoption of the $\mathrm{CE}$ at the organisational level is a challenging job given the linear economy mind-set dominant in most organisations (Ellen MacArthur Foundation, 2013). The speed and scale of the circular transition will depend on knowledge, awareness and engagement of all market participants (Koszewska, 2018). Table 2 presents the challenges of adopting CE.

Table 2: Challenges faced during the adopting circular economy.

\begin{tabular}{|c|c|c|c|c|c|c|c|c|c|c|}
\hline \multirow[t]{2}{*}{ Code } & \multirow[t]{2}{*}{ Challenges } & \multicolumn{8}{|c|}{ Sources } & \multirow[t]{2}{*}{ Count } \\
\hline & & 1 & 2 & 3 & 4 & 5 & 6 & 7 & 8 & \\
\hline C1 & Expensive & * & $*$ & * & * & & * & * & & 6 \\
\hline C2 & Advanced Technology & * & * & & * & * & * & & * & 6 \\
\hline C3 & Measuring the ( financial) benefits & * & & & & * & * & & & 4 \\
\hline $\mathrm{C} 4$ & Lack of knowledge and awareness & * & & * & & & & * & & 3 \\
\hline C5 & $\begin{array}{l}\text { Lack of support, commitment and } \\
\text { leadership }\end{array}$ & * & & & * & & & & * & 3 \\
\hline C6 & Lack of systematic regulation & * & * & & & & * & & & 3 \\
\hline $\mathbf{C}_{7}$ & Lack of social and cultural acceptance & & * & & * & & * & & & 3 \\
\hline C8 & Lack of risk taking attitude & * & & & & $*$ & & & & 2 \\
\hline C9 & Integration between functions & & & & & * & & & & 1 \\
\hline C10 & Missing exchange of information & & & & & * & & & & 1 \\
\hline
\end{tabular}




\begin{tabular}{|l|l|l|l|l|l|l|l|l|l|l|}
\hline C11 & Value chain structures & & & & & $*$ & & & & 1 \\
\hline C12 & Low quality materials & & & & $*$ & & & & & 1 \\
\hline C13 & Lack of infrastructure & & & & & & $*$ & & & 1 \\
\hline C14 & Time consuming & & & & & & $*$ & & \\
\hline C15 & Complexity & & & & $*$ & & & & 1 \\
\hline C16 & Thermodynamic & & & $*$ & & & & & 1 \\
\hline [1- (Jia, et al., 2020), 2-(Boiten, et al., 2020),3-(Gardettia, 2019), 4-(Korhonen, et al., \\
2018), 5- (Ritzena \& Sandstroma, 2017), 6- (Snoek , 2017), 7- (Lofgren \& Enocson, 2014), \\
8- (Geng \& Doberstein, 2008)]
\end{tabular}

Expensive and Advanced technology have been identified as the most noteworthy challenges when adopting CE. The code expensive, Swedish apparel industry as an example, Plam (2011) mentioned that, "there are clear economic barriers in the Swedish apparel market, which hinder the implementation of a CE. That makes it relatively cheaper to produce new garments than recycled or reused old ones, which in turn makes the price of second hand garments not competitive enough compared to new ones". In case of advanced technology, there is a need for major changes in both the products and the production/take-back systems and they were hesitant about how that would work and what it would cost. Additionally, about the quality issue as well (Geng \& Doberstein, 2008). Further, the still largely inadequate technological capability to provide high value recycling of textile fibres was a recurring concern by stakeholders across the case study locations. Next to that, Measuring the (financial) benefits has been cited in four sources. There is an uncertainty about how revenues would be generated through $\mathrm{CE}$ adoption and about what values an increased sustainability of their deliverables would give. These changes also take time, investments and the logic in the financial system are focused on rapid returns on investments and cost saving, making it difficult to convince owners of a long-term system change.

Even though, only two out of eight have been mentioned the Lack of risk taking attitude, it is one of the most prominent barrier, Ritzen and Sandstrom, (2017) stated that "it was the overall large risk aversion and the business logic of taking small safe steps in the development of the organization". Lack of knowledge and awareness, there is unfamiliarity with the CE concept and having a shallow understanding of its meaning, which prohibits an evolutionary change towards CE. Lack of systematic regulation is definitely a challenge to have a dramatic change like introduction of $\mathrm{CE}$ into organisations. Likewise, The European commission (2012) mentioned that tax incentives, increase tax either on specific waste streams and extended producer responsibility, tax in relation to the final amount of waste that is thrown away must be included into regulation as sustainable opportunities in future. If the producer has to pay for how much that is thrown away in the end, it would make them produce more sustainable and recycled products. Moreover, Integration between function is mentioned by only one source, but that is a key challenge to establish CE into organisations as CE is far too complex to be handled by a single department, still it is unclear how the responsibility for CE would be managed within the organisation.

\section{Conclusions and way forward}

The study evaluated the CE concept and its importance in the apparel industry. CE was well established in China, Bangladesh, Europe, Australia and Germany, though it is a novel concept in Sri Lanka. Based on the literature findings, it has been evident that $\mathrm{CE}$ concept has been incorporated successfully within the apparel industry across several countries, providing environmental and economic benefits. However, the paper also presented the key benefits and challenges of adopting $\mathrm{CE}$ concept. The main benefits are environmental gain, economic benefit, resource optimisation and collaboration among stakeholders and the main challenges are expensive, advanced technology, measuring the benefits especially financially, lack of support, knowledge, awareness, commitment and leadership, systematic regulation, social and cultural acceptance. Moreover, this paper lays the 
platform to carry out the research to analyse the applicability of CE in Sri Lankan apparel industry, which is the way forward of this study.

\section{References}

1. Achterberg, E., Hinfelaar, J. \& Bocken, N., 2016. Master Circular Business with the Value Hill. White Paper, p. 18.

2. Allwood, C., Laursen, S., DeRodriguez, C. \& Bocken, N., 2006. Well Dressed? The Present and Future Sustainability of Clothing and Textiles in the United Kingdom. Cambridge: University of Cambridge, Institute for Manufacturing,.

3. Allwood, . J., Laursen, . S., de Rodríquez, C. \& Bocken, N., 2006. Well dressed? The present and future sustainability of clothing and textiles in the United Kingdom. Cambridge, UK.: University of Cambridge, Institute for Manufacturing.

4. Amaral, M. et al., 2018. Industrial textile recycling and reuse in Brazil: case study and considerations concerning the circular economy. Gest. Production.

5. Andersen, M., 2007. An introductory note on the environmental economics of the circular economy. Sustainability Science, Volume 2, p. 133-140.

6. Braungart, M. \& McDonough, W., 2002. Cradle to Cradle: Remaking the Way We Make Things. New York: North Point Press.

7. Choi, T., Chris, K., Wong, C. \& Yee, R., 2012. Green manufacturing and distribution in the fashion and apparel industries. International Journal of Production Economics, 135(2), p. 531.

8. Claudio, L., 2007. Waste couture: environmental impact of the clothing industry. Environmental Health Perspectives, 115(9), pp. 448-454.

9. Cooper, T., 1999. Creating an economic infrastructure for sustainable product design. Journal of Sustainable Design, Volume 8, p. 7-17.

10. Cordon, C., Hald, K. S. \& Seifert, R. W., 2012. Strategic Supply Chain Management. New York: Routledge.

11. Drozdenko, R., Jensen, M. \& Coelho, D., 2011. Pricing of Green Products: Premiums paid, consumer characteristics and incentives. International Journal of Business, 4(1), p. 106.

12. Du, L., Yu, L. \& Cheng, R., 2010. The Construction Research on Rapid-Response Eco-Supply Chain of the Textile Industry Based on the Circular Economy. Wuhan,China , Department of Industry Engineering,Wuhan University of Science and Engineering , pp. 248-251.

13. Echelon Media, 2020. Economynext. [Online] Available at: https://economynext.com/brand_voice/amidst-covid-19-sri-lanka-apparel-is-fighting-for-its-life/) [Accessed 2 May 2020].

14. EDB, 2020. Sri Lanka Export Development Board. [Online] Available at: https://www.srilankabusiness.com/apparel/about/ [Accessed 02 January 2020].

15. Ellen MacArthur Foundation, 2013. Towards the Circular Economy: Economic and Business Rationale for an Accelerated Transition, UK: Cowes.

16. Ellen Macarthur Foundation, 2014. Towards the Circular Economy. Cowes: Ellen Macarthur Foundation.

17. Fink, A., 2005. Conducting Research Literature Reviews: From Paper to the Internet. Thousand Oaks ed. CA: Sage Publications.

18. Fischer, A. \& Pascucci, S., 2017. Institutional incentives in circular economy transition: The case of material use in the Dutch textile industry,. Journal of Cleaner Production.

19. Fulton, K. \& Lee, S., 2010. An overview of sustainability in the fashion industry. The International Journal of Environmental, Cultural, Economic and Social Sustainability, 6(1), pp. 1-14.

20. Gam, H. \& Banning, J., 2011. Addressing sustainable apparel design challenges with problem-based learning. Clothing and Textiles Research Journal, 29(3), pp. 202-219.

21. Geissdoerfer, M., Savaget, P., Bocken, N. \& Hultink, H., 2017. The Circular EconomyeA new sustainability paradigm?. Journal of Clean Production, Volume 143, pp. 757-768.

22. Geng , Y. \& Doberstein, B., 2008. Developing the circular economy in China: Challenges and opportunities for achieving 'leapfrog development'. International Journal of Sustainable Development \& World Ecology, 15(3), pp. 231-239.

23. Geng, Y., Sarkis, J., Ulgiati, S. \& Zhang, P., 2013. Measuring China's Circular Economy. Environment and Development, Volume 339, pp. 1526-1527.

24. Genovesea, A., Acquayeb, A., Figueroaa, A. \& Koha , S., 2017. Sustainable supply chain management and the transition towards a circular economy: Evidence and some applications. Omega, Volume 66, pp. 344-357.

25. Ghisellini, P., Cialani, C. \& Ulgiati, S., 2016. A review on circular economy: the expected transition to a balanced interplay of environmental and economic systems",. Journal of Cleaner Production, Volume 114, pp. 11-32.

26. Giurco, D., Littleboy, A. \& Boyle, T., 2014. Circular Economy: Questions for Responsible Minerals, Additive Manufacturing and Recycling of Metals. Resoruces, Volume 3, pp. 432-453.

27. Gregson, N., Crang, M., Fuller , S. \& Holmes , H., 2015. Interrogating the circular economy: the moral economy of resource recovery in the EU. Economy and Society, 44(2), pp. 218-243.

28. Gullingsrud, A. \& Perkkins, L., 2015. Designing for the circular economy: cradle to Cradle ${ }^{\circledR}$ design. Sustainable Fashion What's Next?. New York: Bloomsbury.

29. Kazancoglu, Y., Kazancoglu, I. \& Muhittin, S., 2018. A new holistic conceptual framework for green supply chain management performance assessment based on circular economy. Journal of Cleaner Production, Volume 192, pp. 1282-1299. 
30. Kenneth, W. et al., 2012. Green supply chain managementpractices: impact on performance. Supply Chain Management: An International Journal, 17(3), pp. 290-305.

31. Korhonen, J., HOnkasalo, A. \& Seppela, J., 2018. The Circular Economy: The Concept and its Limitations. Ecological Economics, Volume 143, pp. 37-46.

32. Koszewska, M., 2018. Circular Economy-Challenges for the Textile and Clothing Industry. AUTEX Research Journal, 18(4), pp. 337-347.

33. Leonas, K., 2017. The use of recycle fibres in fashion and home products. Singapore: Springer.

34. Liu, Q. et al., 2009. A survey and analysis on public awareness and performance for promoting circular economy in China: A case study from Tianjin. Journal of Cleaner Production, Volume 17, p. 265-270.

35. Merli, R., Preziosi, M. \& Acampora, A., 2018. How do scholars approach the circular economy? A systematic literature review.. Journal of Clean Production, Volume 128, pp. 703-722.

36. Moktadir, A. et al., 2017. Drivers to sustainable manufacturing practices and circular economy: a perspective of leather industries in Bangladesh. Journal of Cleaner Production.

37. Murray, A., Skene, K. \& Haynes, K., 2017. The Circular Economy: An Interdisciplinary Exploration of the Concept and Application in a Global Context. Journal of Bussiness Ethics, Volume 140, p. 369-380.

38. Muthukumarana, T. et al., 2017. Life cycle environmental impacts of the apparel industry in Sri Lanka: Analysis of the energy sources. Journal of Cleaner Production.

39. Prieto-Sandoval, V., Jaca, C. \& Ormaza, M., 2017. Towards a consensus on the circular economy. Journal of Cleaner Production.

40. Ranasinghe, R., 2020. Post-COVID19 (Novel CORONA) Economic Recovery: Critical Review on Economic Immunity of Sri Lanka: The Novel Corona Outbreak and Global Developments. [Online] Available at: https://www.researchgate.net/publication/340954038_POSTCOVID19 NOVEL CORONA ECONOMIC RECOVERY CRITICAL REVIEW ON ECONOMIC IMMUNITY OF $S$ RI_LANKA_The_Novel_Corona_Outbreak_and_Global_Developments[Accessed 20 May 2020].

41. Rattalino, F., 2017. Circular advantage anyone? Sustainability-driven innovation and circularity at Patagonia, Inc. Thunderbird. International Business Review, 6o(5), pp. 747-755.

42. Ritzén, S. \& Sandström, G., 2017. Barriers to the Circular Economy - integration of perspectives and domains. Sweden, The 9th CIRP IPSS Conference: Circular Perspectives on Product/Service-Systems.

43. Roos, S., Sandin, G., Zamani, B. \& Peters, G., 2015. Environmental assessment of Swedish fashion consumption. Five garments - sustainable futures. Stockholm, Sweden: Mistra Future Fashion.

44. Sandin, G. \& Peters, G., 2018. Environmental impact of textile reuse and recycling - A review. Journal of Cleaner Production.

45. Sandin, G. \& Peters, G., 2018. Environmental impact of textile reuse and recycling - A review. Journal of Cleaner Production.

46. Sauve, S., Bernard, S. \& Sloan, P., 2016. sustainable development and circular economy: alternative concepts for transdisciplinary research. Environmental Development, Volume 17, pp. 48-56.

47. Shaw, D. et al., 2006. Fashion victim: the impact of fair trade consumers on clothing choice. Journal of Strategic Marketing, 14(14), pp. 427-440.

48. Staicu, D. \& Pop, O., 2018. Mapping the interactions between the stakeholders of the circular economy ecosystem applied to the textile and apparel sector in Romania”, Management \& Marketing. Challenges for the Knowledge Society, 13(4), pp. 1190-1209.

49. Sukumaran , A., 2020. Business news. [Online] Available at: https://www.lankabusinessnews.com/the-impact-on-sri-lankas-apparel-industry-due-to-the-prevalenceof-covid-19/ [Accessed 25 April 2020].

50. Tajuddin, S., 2019. Typology of Circular Economy Models and Competitive Advantages: A case of Apparel Multinationals. [Online]

[Accessed 2 May 2020].

51. Twigger, A., 2016. Shifting perceptions: the Reknit revolution. In: Centre for Circular Design Circular Transitions. London: University of the Arts of London.

52. UNEP, 2006. Circular Economy: An alternative for economic development. Paris: UNEP DTIE.

53. Walker, D., 2008. Sustainability: environmental management, transparency and competitive advantage. Journal of Retail and Leisure Property, 7(2), pp. 119-130.

54. Wilding, R., Wagner, B., Seuring, S. \& Gold, S., 2012. Conducting content-analysis based literature reviews in SCM. Supply Chain Management, 17(5), pp. 544-555.

55. Winge, T., 2008. Green is the new black': celebrity chic and the 'green' commodity fetish. Fashion Theory, 12(5), pp. 511524.

56. Ying, J. \& Li-Jun, Z., 2012. Study on green supply chain management based on circular economy. Physics Procedia, Volume 25, pp. 1682-1688.

57. Zhu, Q., Geng, Y. \& Lai, K., 2010. Journal of Environmental Management. Circular economy practices among Chinese manufacturers varying in environmental-oriented supply chain cooperation and the performance implications, 91(6), pp. 1324-1331. 